International Journal of Current Advanced Research

ISSN: O: 2319-6475, ISSN: P: 2319-6505, Impact Factor: 6.614

Available Online at www.journalijcar.org

Volume 7; Issue 4(H); April 2018; Page No. 11877-11881

DOI: http://dx.doi.org/10.24327/ijcar.2018.11881.2071

Research Article

\title{
SIDE EFFECTS OF MEDICATIONS USED TO TREAT ADHD IN BRAZIL'S PUBLIC HEALTH
}

\section{Silvyo David Araújo Giffoni., Ana Cristina de Castro* and Sylvia Maria Ciasca}

Laboratory of Research in Difficulties Disturbances of Learning and Disorders of Attention DISAPRE

Neurology Department -College of Medical Sciences -UNICAMP -Campinas. Sao Paulo, Brazil.

\section{A R T I C L E I N F O}

\section{Article History:}

Received $17^{\text {th }}$ January, 2018

Received in revised form $26^{\text {th }}$

February, 2018 Accepted $9^{\text {th }}$ March, 2018

Published online $28^{\text {th }}$ April, 2018

Key words:

ADHD-side effects-public health

\begin{abstract}
A B S T R A C T
To diagnose Attention Deficit Hyperactive Disorder (ADHD) accurately and treat it effectively requires a multidisciplinary, multimodal approach that involves psychosocial and psychopharmacological interventions. Characteristics that one may be observed in persons with ADHD include excessive movement of extremities and inability to sit still for extended periods of time, aggressive behavior and sudden mood swings, and carelessness and absent mindedness that may manifest themselves as inattentiveness in class and contribute to impaired academic performance. There is a significantly higher prevalence of ADHD in boys, who are 1.5 to 5.8 times more likely than girls to be diagnosed. The disorder often has a chronic course with about $70 \%$ of affected children presenting threshold symptoms and associated impairments in adolescence and 30 to $50 \%$ presenting them in adulthood. To address such concerns and determine the biosafety of such medications, the present study comprises an assessment of the side effects of medications provided by Brazil's public health service to treat ADHD.
\end{abstract}

Copyright $₫ 2018$ Silvyo David Araújo Giffoni et al. This is an open access article distributed under the Creative Commons Attribution License, which permits unrestricted use, distribution, and reproduction in any medium, provided the original work is properly cited.

\section{INTRODUCTION}

Attention deficit-hyperactivity disorder (ADHD) is a common neuropsychiatric disorder with preschool-age onset. Thought to affect 3 to $5 \%$ of all school-age children (Rohde et al, 1999) (Vasconcelos et al, 2003). It is characterized by easily recognizable symptoms of age-inappropriate hyperactivity, inattentiveness, and impulsivity (Rohde et al, 2004). ADHD is a global health problem, whose effects range from poor academic performance to psychosocial problems. To diagnose ADHD accurately and treat it effectively requires a multidisciplinary, multimodal approach that involves psychosocial and psychopharmacological interventions (Rhode et al, 1999) (Vasconcelos et al, 2003) Obstacles to successful diagnosis and treatment include the prevalence of myths about the disorder (Rohde, 2004).

Characteristics that one may be observed in persons with ADHD include excessive movement of extremities and inability to sit still for extended periods of time, aggressive behavior and sudden mood swings, and carelessness and absent mindedness that may manifest themselves as inattentiveness in class and contribute to impaired academic performance (Knipp, 2006) (Sax, Kautz, 2003).

The current edition of the Diagnostic and Statistical Manual of Mental Health Disorders (DSM-5, 2013) defines ADHD

*Corresponding author: Ana Cristina de Castro Laboratory of Research in Difficulties Disturbances of Learning and Disorders of Attention DISAPRE, Neurology Department College of Medical Sciences -UNICAMP -Campinas. Sao Paulo, Brazil. according to two behavioral domains: inattentiveness and hyperactivity/impulsivity. Each comprises nine possible symptoms, with the presence of at least six required for diagnosis as ADHD. With six or more symptoms of inattention, the diagnosis is the predominantly inattentive type, and with six or more symptoms of hyperactivity-impulsivity, the predominantly hyperactive-impulsive type. With at least six symptoms in the areas of inattention and hyperactivityimpulsivity, the diagnosis is ADHD-combined or mixed (DSM-5, 2013) Eighty percent of children diagnosed with ADHD display symptoms in both domains, though among the overall ADHD population, the predominately inattentive type of is most common (Vascncelos et al, 2003).

The diagnostic criteria for ADHD requires the following:

1. At least six of the following symptoms of inattention have frequently persisted for at least six months to a degree unsuitable for and inconsistent with developmental level:

(a)Failure to pay attention to details or making careless mistakes in school or other work, (b) Difficulty in sustaining attention in tasks or play activities, (c) perception of not listening when spoken to directly (d) failure to follow instructions and complete schoolwork or workplace duties not arising from failure to understand instructions or oppositional behavior, (e) difficulty in organizing tasks and activities (f) avoidance of, aversion to, or unwillingness to engage in tasks that require sustained mental effort, such as schoolwork or domestic shores, (g) losing things required for tasks or activities, such as toys, school assignments, pencils, books, or 
other materials, (h) facile distraction from external stimuli, and (i) forgetfulness in daily activities.

2. At least six of the following symptoms of hyperactivity/impulsivity have frequently persisted for at least six months to a degree unsuitable for and inconsistent with developmental level: hyperactivity (a) fidgeting with hands or feet or moving while seated, (b) leaving seat in classroom or other situations in which remaining seated is expected, (c) running about or climbing excessively in inappropriate situations or in adolescents or adults, subjective feelings of restlessness, (d) difficulty in playing or engaging in leisure activities quietly, (e) restlessness or, on occasion, acting as if driven by a motor, (f) verbosity, impulsivity: (g) often gives answers before questions have been completed (h) difficulty waiting for the appropriate moment to speak, and (i) interrupting or intruding on others, e.g., in conversations or games). ${ }^{6,7}$

Additional DSM-5 criteria stipulate that some inattention and hyperactivity/impulsivity symptoms occur before age seven. Symptoms must also occur in at least two places, e.g., home and school, and cause social, academic, or professional impairment. They should not occur solely during the course of an invasive or schizophrenic or other psychotic disorder or be caused by another primary mental disorder, such as mood, anxiety, or dissociative disorders. The definitive diagnosis depends on the reliability of parent/teacher reports and the experience of doctors and psychologists in interpreting the patient's stories and history (Sax, Kautz, 2003).

There is a significantly higher prevalence of ADHD in boys, who are 1.5 to 5.8 times more likely than girls to be diagnosed. The disorder often has a chronic course with about $70 \%$ of affected children presenting threshold ADHD symptoms and associated impairments in adolescence and 30 to $50 \%$ presenting them in adulthood (Rohde et al,1999) (Vasconcelos et al, 2003).

The presence of comorbid disorders is the rule rather than the exception. Common comorbidities in children and adolescents include oppositional defiant disorder, conduct disorder, anxiety disorders, mood disorders, tic disorders, motor coordination disorder, learning disabilities, and problems in reciprocal social interaction and communication analogous to those described in autism spectrum disorders. In adolescence and adulthood, comorbid risk-taking behaviors, substance abuse disorders, antisocial personality disorder, and borderline personality disorder are increasingly prevalent. Numerous problems are associated with ADHD, such as poor academic performance, dropping out of school, social isolation, and reduced occupational success (Rohde et al,2004) (Poeta, Rosa Neto, 2004).

There is not a universal protocol for the treatment of ADHD, and, in general, each country determines its recommendations based on the literature (Hodgkings, Shaw, Hetchman, 2012). There is, however, a consensus for the necessity of a comprehensive, multi-modal treatment plan, developed collaboratively by the physician, therapists, psychologists, family, and school, that integrates psychoeducation, caregiver training, educational and behavioral intervention, and medication, among other factors, to create an optimal treatment environment.
The United States Food and Drug Administration (FDA) has approved the use of methylphenidate; mixed amphetamine salts, including the recently introduced prodrug, lisdexanfetamine, a selective reuptake inhibitor of norepinephrine (atomoxetine); and sympatholytic antiadrenergic agents, such as clonidine and guanfacine. Bupropion, which inhibits reuptake of dopamine and norepinephrine, and tricyclic antidepressants, including imipramine, are listed in U.S. guidelines as medication options for ADHD (Pliszka et al, 2006) but are not FDA-approved for this use.

About 4 children with ADHD, 3 received medicine as treatment. The American Academy of Pediatrics recommend training parents of young children in behavior therapy before prescribing medicine. Also points out very important actions of the federal government, health professionals and parents getting training in behavior therapy, Centers for Disease Control and Prevention -CDC, on National Center on Birth Defects and Developmental Disabilities (2016).

In Australia, methylphenidate and amphetamines are recommended as first-line treatments, while in Canada, a longacting methylphenidate, amphetamines, and atomoxetine are so regarded (Hodgkings, Shaw, Hetchman, 2012)

In Europe, psychoeducation and behavioral intervention are recommended as first-line therapy for preschool and school age children with ADHD and moderate impairment. In severe cases that fail to respond to psychoeducation and behavioral intervention, methylphenidate or long-term atomoxetine is the indicated drug treatment. UK treatment algorithms recommend methylphenidate and atomoxetine as first- and second-line treatments respectively ( Taylor et al, 2004).

In Brazil, first-line medications are long-acting methylphenidate, lisdexanfetamine, and atomoxetine, with clonidine as a second-line alternative. Other drugs, such as bupropion and imipramine, are also widely used. Not all are available through the public health service, the most common being methylphenidate, imipramine, and derivatives. In some regions, caffeine is still being used because it is readily available.

Although ADHD has been firmly established as a disorder that meets the criteria for the validation of psychiatric diagnoses (Robins, Guze, 1970) (Faraone, 2005) the validity of the disorder has been challenged by media, journalists, politicians, and even some medical, as well as nonmedical, health professionals in large-scale anti-medicalization campaigns. From this critics diagnosis, ADHD would be caused by inadequate parenting and schooling in a society with high demands for children's self-control and organization (Buitelaar, Rothenberger, 2004) Concerns are expressed concerning over diagnosis and treatment, particularly the dangers of using psychostimulants. Despite their absence of a clinical, academic basis, such claims have adversely affected acceptance of the ADHD diagnosis and appropriate treatment of children with the disorder (Buitelaar, Rothenberger, 2004) ( Faraone, 2005).

To address such concerns and determine the biosafety of such medications, the present study comprises an assessment of the side effects of medications provided by Brazil's public health service to treat ADHD. 


\section{METHODS}

The objective of this study is to evaluate the side effects of medications used by the municipal public health services of Campinas and Paulinia in the state of Sao Paulo to treat ADHD, methylphenidate immediate release (MPH-IR), methylphenidate spheroidal oral drug absorption system (MPH-SODAS), methylphenidate osmotic release oral system (MPH-OROS), imipramine, caffeine, and drug combinations.

A total of 297 patients with ADHD were evaluated at the pediatric neurological clinic of the Universidade Estadual de Campinas' Research Laboratory in Learning Disabilities and Attention Disorders and Paulínia's Center of Therapy and Rehabilitation. Inclusion criteria comprised the following: age between 7 and 14 years, diagnosis by an interdisciplinary team, presence of side effects after initial month of use. Side effects during the first month were not considered since most were temporary, minor adaptations to the drug. Patients and relatives completed an open questionnaire about medications used in treating ADHD and the side effects that occurred. (Table1).

\section{RESULTS}

Subject age ranged from 7 to 14 years, with 224 males and 73 females. Medications used were distributed as follows: MPHIR, 168; MPH-SODAS, 37; MPH-OROS, 15; lisdexanfetamine; 12, imipramine, 45; and drug combinations, 20.

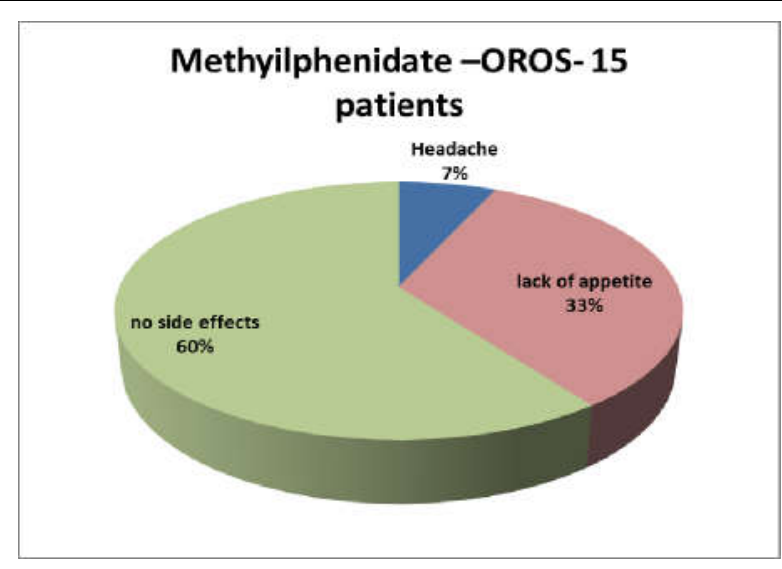

Figure 3
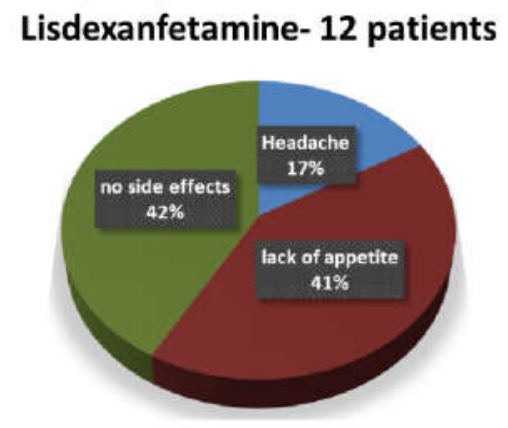

Figure 4

Table 1 Side effects as reported by subjects

\begin{tabular}{|c|c|c|c|c|c|c|c|c|}
\hline Medication & Users & Headache & Sleeplessness & Agitation & Anxiety & Insomnia & Abdominal pain & Lack of appetite \\
\hline MPH-IR & 168 & 24 & 4 & 4 & 16 & 3 & 13 & \\
\hline MPH-SODAS & 37 & 2 & & 2 & & & & 12 \\
\hline MPH-OROS & 15 & & & 1 & & & & 5 \\
\hline Lisdexanfetamine & 12 & 2 & & & & & & 5 \\
\hline Imipramine & 45 & & 10 & & & & 4 & 2 \\
\hline Drugs Combination & 20 & 3 & 2 & & 3 & & & \\
\hline
\end{tabular}

*Aggressiveness: was not reported

\section{Methyilphenidate- LI- 168 patients}

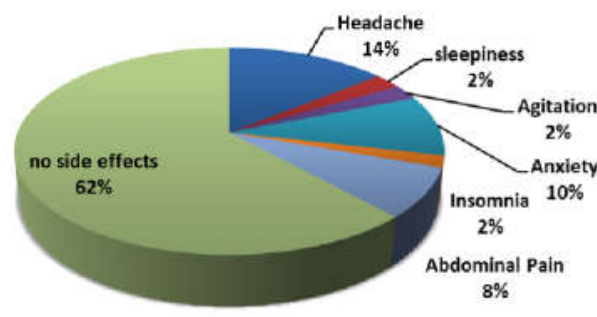

Figure 1

\section{Methyilphenidate - SODAS- 37 patients}

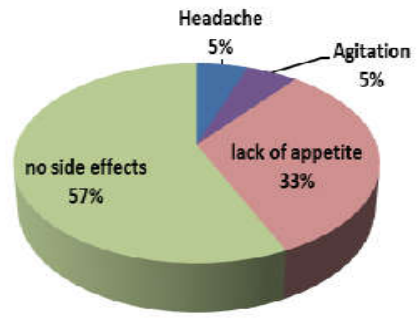

Figure 2
Of the 168 subjects using MPH-IR, 55 (35.7\%) presented side effects, with 8 patients presenting more than one. The most frequent were headache, anxiety, and abdominal pains. Of the 37 using MPH-SODAS, 16 (43.2\%) presented side effects, with lack of appetite, agitation, and headache most common. Among the 15 using MPH-OROS, 6 (40.0\%) presented side effects, with 5 presenting lack of appetite and 1 agitation. Among the 12 using lisdexanfetamine, 7 (58.3\%) presented side effects, with 5 presenting lack of appetite and 2, a headache. Of the 45 subjects using imipramine 14 (31.1\%) presented side effects, with 2 presenting more than one complaint, abdominal pain and lack of appetite. Of the 20 using a combination of drugs. 7 (35.0\%) presented side effects, chiefly, headache, anxiety, and sleeplessness.

\section{DISCUSSION}

The treatment of ADHD is challenging and often involves medication integrated with other support therapies such as clinical and educational psychology, behavioral intervention, and speech therapy, among others, depending on the patient's needs (Sax, Kautz, 2003) (Barkley, 2004) (Sonuga-Bark et al 2011).

There has been considerable discussion in the literature about the use of particular medications in treating ADHD and their side effects (Knipp, 2006) (Kim et al, 2010), but few studies 
have evaluated the spectrum of first-line drugs used in its treatment in a comprehensive manner.

Use of MPH-OROS does not usually alter the sleep pattern, but it may, in some cases, improve the sleep of ADHD patients who experience disturbance in initial sleep (Kim et al, 2010). Tobaiqy and colleagues found a larger number of subjects experienced side effects $(66 \%)$ because they used the open questionnaire used in this paper combined with a checklist ( Kim et al, 2010). For methylphenidate, the most frequently reported side effects were loss of appetite (34.3\%), headache (17.9\%), mood and emotional problems (14.9\%), stomach upset $(14.9 \%)$, sleep disturbance $(10.4 \%)$, and rash and other skin problems $(5.2 \%)$. The checklist listed 467 possible side effects, and the most frequently reported were mood and emotional problems $(28.1 \% \quad[131 / 467])$, stomach and abdominal problems (13.3\% [62/467]), insomnia (12.8\% [60/467]), and lack of appetite (12.6\% [59/467]). The checklist identified a broader range of potential side effects than those reported as free-text.

The literature reports several common adverse effects associated with the use of methylphenidate and amphetamines (Hodgkins, Shaw, Hetchman, 2006) (Pliszka et al, 2006). Over $10 \%$ of patients using methylphenidate present fatigue, loss of appetite, irritability, and anxiety. Among users of mixed amphetamine salts, the principal complaints were stomach pain, irritability, anxiety, loss of appetite, fatigue, and headache.

In crossover studies, appetite suppression and insomnia were commonly reported as the most common for both stimulants, with elevated rates at higher doses (Hodgkins, Shaw, Hetchman, 2006).

Sonuga-Barke and colleagues (Soniga-Barke et al, 2011) used the Barkley Stimulant Side Effects Rating Scale (BSSERS) BSSERS has six factors: sleep/appetite, dizziness, pain, emotionality, disengagement, and lack of interest. Treatment effects were found only for emotionality, which improved, and sleep and appetite, which worsened. Adverse events were not predictable from subjects' personal and clinical characteristics. Sleep/appetite adverse events were not associated with therapeutic effects. Improvements in attentiondeficit/hyperactivity disorder (ADHD) and emotionality were correlated (Sonuga et al, 2009).

A frequent concern raised by parents relates to children's growth. Prolonged medication with short-acting MPH has been shown to have minimal impact on height during the first 6 months of use; however, catch-up growth was detected during adolescent period (Moungnoi, Maipang, 2011).

The present study found a low rate of use of long-term methylphenidate, i.e., MPH-OROS, MPH-SODAS, and lisdexanfetamine. This may arise from the impact of their higher costs on the public health budget. Similar reasons may contribute to the use of such second-line medications as imipramine and caffeine.

This study delineates the principal side effects of medications used by the public health system to treat persons with ADHD in Brazil. The results, which are further substantiated by using an open questionnaire rather than a checklist, evidence that these medications are generally safe.

\section{CONCLUSION}

In Brazil, as in many other countries, methylphenidate is the most commonly used medication for treating ADHD. It is a relatively safe drug with few side effects, which can be reduced even further by using long-term formulations.

\section{References}

1. American Psychiatric Association. Diagnostical and Statistical Manual of Mental Disorders. 5th ed. Washington DC: American Psychiatric Association; 2013.

2. Barkley RA. Adolescents with attentiondeficit/hyperatcitivy disorders: an overview of empirically based treatments. J Psychiatr Pract, 10:3956,2004

3. Becker SP, Froehlich TE, Epstein JN. Effects of Methylphenidate on Sleep Functioning in Children with Attention-Deficit/Hyperactivity Disorder. Journal of developmental and behavioral pediatrics: JDBP. 2016;37(5):395-404.

doi:10.1097/DBP.0000000000000285.

4. Buitelaar JK, Rothenberger A. Foreword ADHD in the scientific and political context. Eur Child Adolesc Psychiatry. 2004; 13 Suppl 1:I1-6.

5. CDC - Centers for Disease Control and prevention .ADHD in young children, may 2016. Available https://www.cdc.gov/vitalsigns/adhd/

6. Faraone SV. The scientific foundation for understanding attention-deficit-hyperactivity disorder as a valid psychiatric disorder. Eur Child Adolesc Psychiatr 14(1): $1-10,2005$

7. Hodgkins P, Shaw M, Coghill D, Hechtman L. Amfetamine and methylphenidate medications for attention-deficit/hyperactivity disorder: complementary treatment options. Eur Child Adolesc Psychiatry. 2012 Sep; 21(9):477-92.

8. Kim HW, Yoon IY, Cho SC, Kim BN, Chung S, Lee H, Kim CW, Park SK, Yoo HJ. The effect of OROS methylphenidate on the sleep of children with attentiondeficit/hyperactivity disorder. Int Clin Psychopharmacol. 2010. Mar; 25(2):107-15.

9. Knipp DK. Teens' perceptions about attention deficit/hyperactivity disorder and medications. $J$ Sch Nurs, 22:120-5, 2006.

10. Moungnoi P, Maipang P. Long-term effects of shortacting methylphenidate on growth rates of children with attention deficit hyperactivity disorder at Queen Sirikit National Institute of Child Health. J Med Assoc Thai. 2011 Aug; 94 Suppl 3:S158-63.

11. Pliszka SR, Crismon ML, Hughes CW, Corners CK, Emslie GJ, Jensen PS, McCracken JT, Swanson JM, Lopez M. The Texas Children's Medication Algorithm Project: revision of the algorithm for pharmacotherapy of attention-deficit/hyperactivity disorder. $\mathrm{J} \mathrm{Am} \mathrm{Acad}$ Child Adolesc Psychiatry 45:642-657, 2006.

12. Poeta LS, Rosa-Neto F. Estudo epidemiológico dos sintomas do transtorno do déficit de atenção/hiperatividade e transtornos de comportamento em escolares da rede pública de Florianópolis usando a EDAH. Rev Bras Psiquatr, 26:150-5, 2004.

13. Robins E, Guze SB. Establishment of diagnostic validity in psychiatric illness: its application to 
schizophrenia. Am J Psychiatry. 1970 Jan; 126(7):9837. Apud Faraone SV. The scientific foundation for understanding attention-deficit-hyperactivity disorder as a valid psychiatric disorder. Eur Child Adolesc Psychiatr 14(1): 1-10, 2005.

14. Rohde LA et al. ADHD in a school sample of Brazilian adolescents: a study of prevalence, comorbid conditions and impairments. J Am Acad Child Adolesc Psychiatry, 6:716-22, 1999.

15. Rohde LA, Halpern R. Transtorno de déficit de atenção/hiperatividade: atualização. $J$ Pediatr, 80(2 suppl): S61-70, 2004.

16. Rohde, LA., Miguel Filho, Eurípedes Constantino, Benetti, Lúcia et al. Transtorno de déficit de atenção/hiperatividade na infância e na adolescência: considerações clínicas e terapêuticas, Rev. psiquiatr. clín. vol.31 no.3 São Paulo 2004

17. Sax L, Kautz KJ. Who first suggests the diagnosis of attention-deficit/hyperactivity disorder? Ann Fam Med, 1:171-4, 2003.
18. Sonuga-Barke EJ, Koerting J, Smith E, McCann DC, Thompson M. Early detection and intervention for attention-deficit/hyperactivity disorder. Expert Rev Neurother. 2011 Apr; 11(4):557-63.

19. Sonuga-Barke EJ, Coghill D, Wigal T, DeBacker M, Swanson J. Adverse reactions to methylphenidate treatment for attention-deficit/hyperactivity disorder: structure and associations with clinical characteristics and symptom control. J Child Adolesc Psychopharmacol. 2009 Dec; 19(6):683-90.

20. Taylor E, Dopfner M, Sergeant J, Asherson P, Banaschewski T, Buitelaar J, Coghill D, Danckaerts M, Rothenberger A, Sonuga- Barke E, Steinhausen HC, Zuddas A (2004) European clinical guidelines for hyperkinetic disorder-first upgrade. Eur Child Adolesc Psychiatry 13(Suppl 1):I7-I30.

21. Vasconcelos, Marcio M., Werner Jr., Jairo, Malheiros, Ana Flávia de Araújo et al. Prevalência do transtorno de déficit de atenção/hiperatividade numa escola pública primária. Arq. Neuro-Psiquiatr., Mar 2003, vol.61, no.1, p.67-73.

\section{How to cite this article:}

Silvyo David Araújo Giffoni et al (2018) 'Side Effects of Medications Used to Treat Adhd in Brazil's Public Health', International Journal of Current Advanced Research, 07(4), pp. 11877-11881.

DOI: http://dx.doi.org/10.24327/ijcar.2018.11881.2071 